\title{
Synthesis and characterization of thiol-polystyrene microsphere and its adsorption properties of thallium
}

\author{
Youze Xu${ }^{1}$, Yuehui Chen ${ }^{2 *}$, Yuanyuan Zhao ${ }^{1 *}$, Shuang Zhou ${ }^{1}$, Guangyi Fu ${ }^{1}$, Yu Zhong ${ }^{1}$ \\ ${ }^{1}$. Key Laboratory of Water Pollution Control Technology, Hunan Research Academy of Environmental Science, Changsha Hunan \\ 410004 \\ 2. Department of Environmental Science and Engineering, College of Environment and Resources, Xiangtan University, Xiangtan, \\ 411105
}

\begin{abstract}
Thallium ( $\mathrm{Tl}$ ) is highly toxic in the environment. In order to solve the harm of Tl pollution to the environment, thiol-polystyrene microsphere (TPM) with good adsorption properties for Tl were prepared in this paper. The GAUSSIAN software was used to calculate the adsorption performance of the $\mathrm{TPM}$ on $\mathrm{Tl}^{+}$, and the adsorption mechanism was discussed. The thermogravimetric analysis show that the TPM prepared with chloromethyl polystyrene microspheres (CPM) and thiourea as the main raw materials has good chemical thermal stability. In the $\mathrm{Tl}^{+}$solution of $1 \mathrm{mg} / \mathrm{L}$, the adsorption and removal rate of the TPMs in was $99 \%$, with a significant adsorption of $\mathrm{Tl}^{+}$properties. When the dosage of $\mathrm{TPM}$ is $0.4 \mathrm{~L} / \mathrm{g}, \mathrm{pH}$ is $6-10$, temperature is $5-20{ }^{\circ} \mathrm{C}$, and adsorption time reaches $640 \mathrm{~min}$, thallium-containing water with $\mathrm{Tl}^{+}$ concentration of $5 \mathrm{mg} / \mathrm{L}$ can be treated to within the national discharge standard $(5 \mu \mathrm{g} / \mathrm{L})$. The analytical effect of $0.5 \mathrm{~mol} / \mathrm{L}$ dilute sulfuric acid on TPM can reach $99.96 \%$, and the adsorption capacity of TPM on $\mathrm{Tl}^{+}$is reduced by only $0.1 \%$ after repeated use 4 times, which has good regeneration performance. The modified polystyrene microspheres were characterized by EDS, FT-IR, Raman spectra and XPS, and it was proved that the TPM were ligated with $\mathrm{Tl}^{+}$through the grafted mercapto group, so as to adsorb and remove $\mathrm{Tl}^{+}$from the solution. According to the isotherm and kinetic model of TPM adsorption $\mathrm{Tl}^{+}$, the maximum saturated adsorption amount of TPM to $\mathrm{Tl}^{+}$can reach $3.47 \mathrm{mg} / \mathrm{g}$, mainly chemical adsorption, and the membrane diffusion stage is the main control step of TPM adsorption $\mathrm{Tl}^{+}$. The results showed that the TPM could be a promising adsorbent with good adsorption capacity and reusability for $\mathrm{Tl}^{+}$removal from wastewater
\end{abstract}

\section{Introduction}

In the natural environment, the $\mathrm{Tl}$ exists mainly in various sulfides (such as silver, antimony, arsenic and other sulfides) ore, chalcopyrite, pyrite, silicate and other minerals ${ }^{1}$. Tl is highly toxic and its toxicity to mammals is higher than arsenic, lead, mercury, copper and zinc $^{2-4}$. It has also serious health effects on humans by the food chain ${ }^{5}$. Tl poisoning can cause damage or change of nerve cells and mitochondria in animals, which can cause gastroenteritis, multiple neuropathy and hair loss, and even can pose a threat to human life under high dose intake, ${ }^{6,}$. The World Health Organization defined Tl poisoning when the concentration of $\mathrm{Tl}$ in human urine is at the range of $4.5-6 \mu \mathrm{g} / \mathrm{L}^{8}$, and the minimum lethal dose to the human is at the range of $10-15 \mathrm{mg} / \mathrm{kg}^{9}$.

$$
\text { Nowadays, treatment methods for }
$$
thallium-containing wastewater include oxidation-flocculation $^{10,}{ }^{11}$, chemical precipitation ${ }^{12}$, solvent extraction ${ }^{13,14}$, ion exchange ${ }^{15,16}$, adsorption ${ }^{17-20}$ and some composite methods based on the above ways. Tang et al. ${ }^{21}$ synthesized a novel titanium ferromagnetic nano-adsorbent for the treatment of thorium-containing wastewater, and the removal rate of $\mathrm{Tl}^{+}$could reach $83 \%$ in 30 minutes. Mueller et al. ${ }^{22}$ investigated sulphuric acid-reducing bacteria to produce cerium sulfide $\left(\mathrm{Tl}_{2} \mathrm{~S}\right)$ precipitates, thereby reducing the concentration of $\mathrm{Tl}$ from wastewater. Reddy et al. ${ }^{23}$ recycled the $\mathrm{Tl}$ from the lead smelting dust by solvent extraction and reduction conversion. The results showed that the extraction rate of $\mathrm{Tl}$ reached 99\%. Quintas et al. $^{24}$ treated thallium-containing wastewater in the environment with a raw and L-cysteine chemically modified yerba mate derived from domestic waste, and the results showed that the adsorption material had the largest biosorption capacity at $328 \mathrm{~K}$. Amin et al. ${ }^{25}$ fixed the $\mathrm{Tl}$ on the styrene divinylbenzene anion exchange resin, then measured the absorbance of Tl at $636 \mathrm{~nm}$ and $830 \mathrm{~nm}$. The method has been successfully application to test $\mathrm{Tl}$ in water. However, there are still many problems in the treatment of thallium-containing wastewater by the above methods. For example, the chemical precipitation method is difficult to meet the discharge standard after the thallium-containing wastewater treatment, the biological method is demanding on the treatment conditions, and the solution extraction method is only effective for the treatment of specific thallium-containing wastewater, and the composite method is difficult to operate. Therefore, it

*Corresponding author. E-mail: zyyhjgc0601@163.com (Yuanyuan Zhao) and 61080510@qq.com (Yuehui Chen) 
is a major demand to develop a simple and efficient method for treating wastewater containing $\mathrm{Tl}$ for promoting the sustainable development of the involved enterprises and ensuring the ecological environment and personal safety.

Previous reports indicate that cysteine and glutathione containing thiol groups are involved in the synthesis of some proteins and enzymes in vivo, and thus their special structure makes the sulfhydryl groups easy to combine with heavy metals ${ }^{26}$. Tl and thiol group also have a high affinity ${ }^{27}$, resulting in the inability to synthesize proteins and enzymes in the organism and showing pathological phenomena. Since the thiol group contains unpaired lone pairs of electrons, a coordination bond can be formed with the heavy metal ion. Yang et al. ${ }^{28}$ reported that mercapto-modified resin has certain adsorption to gold, and the recovery rate reached $90 \%-100 \%$. Utkelov et al. ${ }^{29}$ used CPM as raw materials to graft amino propylene to obtain a sulfhydryl chelating resin having three donor atom reactive groups, and the $\alpha$-position contains a sulfhydryl group, which can form a strong bond with the metal ion.

Therefore, this thesis intends to use polystyrene microspheres for the treatment of thorium-containing wastewater by utilizing the high affinity between thiol groups and thallium. Moreover, the thiol-modified polystyrene microspheres has certain reproducibility, the synthesis method is simple, and the particle size is controllable $^{30}$, which has a high application prospect in the selection of the thallium-containing wastewater.

\section{Materials and Method}

\subsection{Materials}

CPM (Nankai University Chemical Plant), thiourea, sodium hydroxide, hydrochloric acid, nitric acid, absolute ethanol, $\mathrm{Pb}^{2+}, \mathrm{Zn}^{2+}, \mathrm{Tl}^{+}$standard solution.

\subsection{Preparation and Characterization of TPM}

$7.5 \mathrm{~g}$ of a mixture of CPM and thiourea in a mass ratio of 2:1 was added in $30 \mathrm{~mL}$ of absolute ethanol, and then heated in a water bath at $50^{\circ} \mathrm{C}$ for $6 \mathrm{~h}$. After the reaction, the obtained microspheres were rinsed with pure water, and the washed microspheres were poured into a $50 \%$ sodium hydroxide solution and hydrolyzed at $70^{\circ} \mathrm{C}$ for 10 hours to obtain TPM. The sample was washed with pure water and then rinsed with 5\% dilute hydrochloric acid. The final product was washed several times and vacuum dried at $50^{\circ} \mathrm{C}$ for $6 \mathrm{~h}$.

The physical and chemical properties of the TPM were tested by optical microscopy, specific surface area analysis, elemental analysis, Raman spectroscopy, and thermogravimetric analysis.

\subsection{Adsorption ability of TPM}

Gaussian view5 software was used to construct the model of TPM combined with different heavy metal ions, and the stable configuration and frontier orbital energy of the structure were calculated by the Ground State module DFT algorithm in Gaussian09W. The calculation of the structure of sulfhydryl and benzene rings was based on $6-311 \mathrm{G}+(\mathrm{d}, \mathrm{p})$ group, heavy metal ions adopt the LanL2DZ basis group.

$10 \mathrm{~mL}$ of $\mathrm{TI}^{+}(4 \mathrm{mg} / \mathrm{L}), \mathrm{Zn}^{2+}(4 \mathrm{mg} / \mathrm{L})$ and $\mathrm{Pb}^{2+}(4$ $\mathrm{mg} / \mathrm{L})$ simulated wastewater were added to a series of 50 $\mathrm{mL}$ centrifuge tubes, respectively, and $0.1 \mathrm{~g}$ of TPM was added. The initial $\mathrm{pH}$ of the solution was adjusted to 7 , and the reaction conditions were also adjusted. The mixture was shaken under the temperature of $25^{\circ} \mathrm{C}$ and a rotation speed of $180 \mathrm{rpm}$, and the adsorption reaction time was $640 \mathrm{~min}$. After the reaction was completed, the microspheres were allowed to settle for $30 \mathrm{~s}$. The supernatant was taken to measure the remaining concentrations of $\mathrm{Tl}^{+}, \mathrm{Zn}^{2+}$ and $\mathrm{Pb}^{2+}$, and the adsorption removal rate was calculated.

\subsection{Single factor influence experiment}

The thallium-containing wastewater with a concentration of $5 \mathrm{mg} / \mathrm{L}$ was placed in a series of conical flasks in varying volume in the presence of $0.1 \mathrm{~g}$ TPM. The $\mathrm{pH}$ was adjusted to neutral, and the reaction kept for $600 \mathrm{~min}$ at the temperature of $25^{\circ} \mathrm{C}$. Firstly, for the optimum dosage of TPM during the process, the effects of different dosages of TPM on the adsorption of $\mathrm{Tl}^{+}$were investigated. Secondly, the optimum adsorption time was determined with the unparalleled dosage of TPM at the same $\mathrm{pH}$ value and temperature. Finally, under the optimum adsorption time and the optimum dosage, the influence of the $\mathrm{pH}$ and temperature on adsorption was investigated.

\subsection{Adsorption isotherms and kinetics}

Three groups of $30 \mathrm{~mL}$ of thallium-containing wastewater with varying concentration of $\mathrm{Tl}^{+}$(from 8 to $20 \mathrm{mg} / \mathrm{L}$ ) were placed in $50 \mathrm{~mL}$ of centrifuge tubes, respectively. After adjusting the initial $\mathrm{pH}$ to 7 , each group in the presence of $0.1 \mathrm{~g}$ TPM was stirred at $180 \mathrm{rpm}$ for $12 \mathrm{~h}$ at 5 , $15,25^{\circ} \mathrm{C}$, respectively. Then, the concentration of $\mathrm{Tl}^{+}$in the supernatant was measured, and the amount of adsorption of TPM was calculated.

\subsection{Recycling experiment}

The microspheres were desorbed with different concentrations of dilute sulfuric acid. The details are as follows: adding $30 \mathrm{~mL}$ of dilute sulfuric acid with concentration of $0.1,0.2,0.3,0.4$ and $0.5 \mathrm{~mol} / \mathrm{L}$ in a $50 \mathrm{~mL}$ centrifuge tube in the presence of $0.3 \mathrm{~g}$ adsorbed TPM, respectively. Next, these tubes were stirred for $10 \mathrm{~h}$ in a constant temperature of $25^{\circ} \mathrm{C}$ shaking incubator. After standing for $30 \mathrm{~s}$, the microspheres were allowed to sink to the bottom, and the concentration of $\mathrm{Tl}^{+}$in the solution was measured to calculate the desorption efficiency. 
For recycling experiment, the used TPM in the suspension was gathered from after each run by vacuum filtration, and washed several times by the double distilled water until neutral $\mathrm{pH}$. Then the washed catalyst dried overnight in oven at $65^{\circ} \mathrm{C}$.

The "adsorption-desorption-adsorption" experiment was repeated 4 times to determine the regeneration performance of TPM.

\section{Result and Discussion}

\subsection{Physical and chemical properties of TPM}

Fig.1 shows that the TPM are regular spheres with an average particle size of $0.5 \mathrm{~mm}$ and a smooth surface, which is a pale yellow microsphere. The specific surface area of TPM was investigated. As shown in Table 1, the modified TPM has a lower specific surface area than the unmodified ones, and the resins have larger particle sizes $^{31}$. The microspheres with a larger particle size are easier to perform solid-liquid separation in the process than the smaller particle size microspheres, and the larger specific surface area is beneficial to the adsorption site of $\mathrm{Tl}^{+}$on the microspheres in the wastewater.

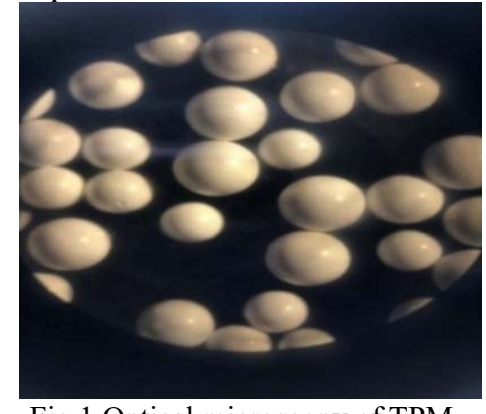

Fig.1 Optical microscopy of TPM

To understand the chemical properties of TPM, energy dispersive spectrometer was applied and the analysis results are shown in Table 1.

Table.1 Pore and surface characteristics of resins

\begin{tabular}{ccc}
\hline Items & CPM & TPM \\
\hline $\mathrm{S}_{\text {BET }}\left(\mathrm{m}^{2} / \mathrm{g}\right)$ & 59.7 & 48.9 \\
$\mathrm{~V}_{\mathrm{t}}\left(\mathrm{cm}^{3} / \mathrm{g}\right)$ & 50.6 & 37.1 \\
$\mathrm{R}_{\mathrm{m}}(\mathrm{nm})$ & 0.614 & 0.503 \\
\hline
\end{tabular}

It can be seen from the table that TPM has a lower level of chlorine than that before modification, and the amount of sulfur is significantly improved, which may indicate that the thio-substituted chloromethyl group is supported on the microspheres. The sodium appeared after modification may attribute to the washing process using $\mathrm{NaOH}$. In order to further prove the chemical structure of the TPM, the functional group structure is analyzed by Raman spectroscopy, which could promote the thiol group to easily visualize in the infrared spectrum $^{27}$. The results are shown in Fig. 2. As shown in Fig 2, the $\mathrm{C}-\mathrm{Cl}$ peak at $678 \mathrm{~cm}^{-1}$ after modification disappears, and a new peak appears at $2560 \mathrm{~cm}^{-1}$, corresponding to $-\mathrm{SH}$ group $^{32}$. This trend indicates that the thiol group replaced the chloromethyl group successfully and loaded on the microspheres. After adsorption, the $-\mathrm{SH}$ peak disappeared since $\mathrm{Tl}^{+}$binds to the sulfhydryl group ${ }^{33}$.

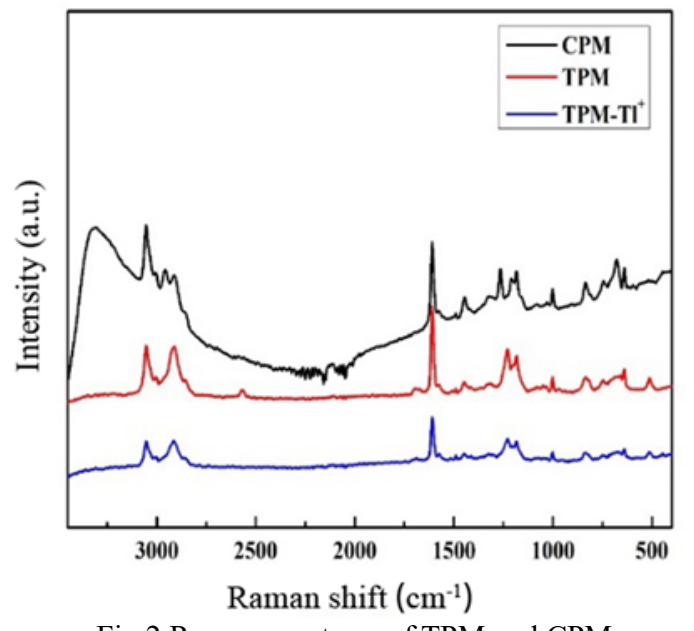

Fig.2 Raman spectrum of TPM and CPM

The thermogravimetric analysis was displayed in in Fig. 3 for determining the chemical stability of the TPM. As can be seen from the Fig.3, the microspheres have been experienced three mass losses from 0 to $800^{\circ} \mathrm{C}$. The first mass loss occurred around $150^{\circ} \mathrm{C}$. This is because the water contained the sample at which evaporates. The second mass loss occurs at $320^{\circ} \mathrm{C}$ because the sulfhydryl groups on the microspheres are thermally decomposed. The third time is $410^{\circ} \mathrm{C}$, at which temperature the structure of carbon chains is destroyed ${ }^{31}$. It can also be seen from the results that the thermal stability of the TPM is good, and the chemical structure of the TPM is not changed less than $300^{\circ} \mathrm{C}$. Therefore, the TPM are available for the treatment of thallium-containing wastewater in the mild environment.

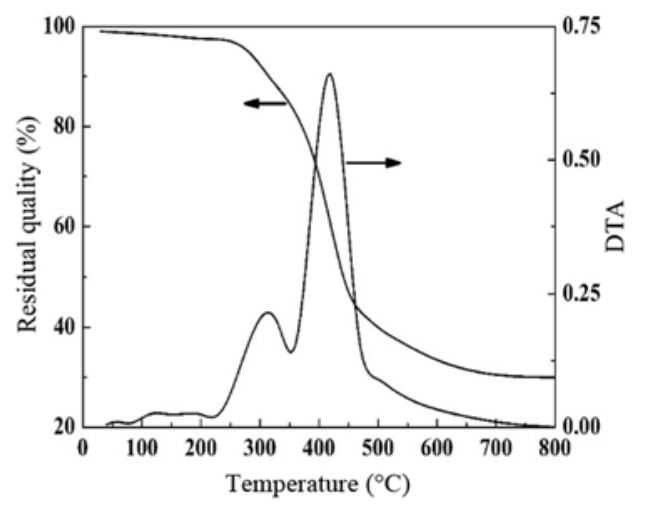

Fig.3 TGA curve of TPM

In order to determine the adsorption performance of the prepared TPM on $\mathrm{Tl}^{+}$, the adsorption effect of microspheres on $\mathrm{Tl}^{+}$before and after modification was measured, and the results are shown in Fig.4. The CPM before modification have basically no adsorption capacity for $\mathrm{Tl}^{+}$, indicating that the chemical groups and physical structures existing in them do not have any effect on the adsorption; Adsorption removal rate of modified tpm for $\mathrm{Tl}+$ increased from $5 \%$ to $99.9 \%$, indicating that the modified polystyrene microspheres had a significant adsorption effect on $\mathrm{Tl}^{+}$, and the adsorption effect was mainly caused by the supported thiol groups. This result is consistent with previous research $^{34}$. 


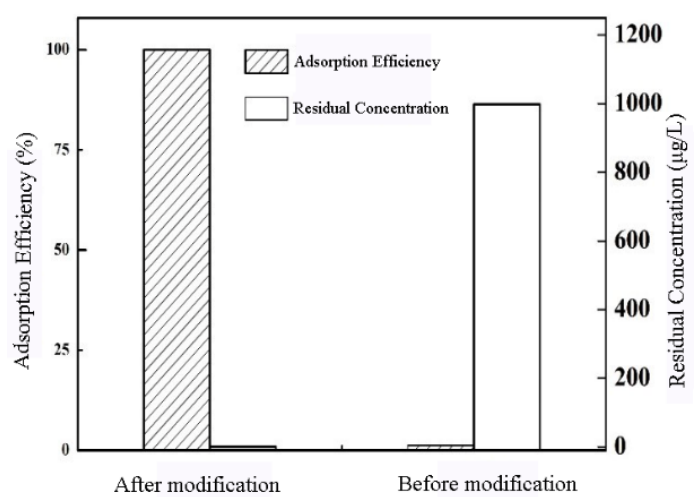

Fig. 4 Adsorption removal rate of $\mathrm{Tl}^{+}$before and after the modification of TPM

\subsection{Adsorption ability of TPM}

The stable configuration and frontier orbital energy of between the TPM and heavy metal ions were calculated according to GAUSSIAN software ${ }^{31}$ (Fig.5 and Table 2).

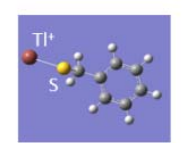

$\mathbf{T r}^{+}$(构型)

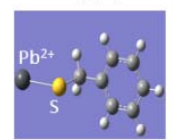

$\mathrm{Pb}^{2+}$ (构型)

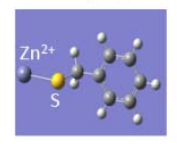

$\mathrm{Zn}^{2}+($ 构型 $)$

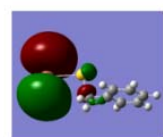

$\mathrm{Tr}^{+}$(LUMO)

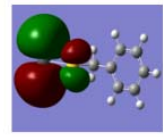

$\mathrm{Pb}^{2+}$ (LUMO)

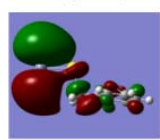

$\mathrm{Zn}^{2+}$ (LUMO)

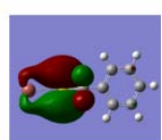

$\mathrm{Tr}^{+}$(номо)

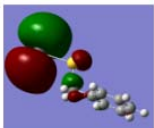

$\mathrm{Pb}^{2+}$ (номо)

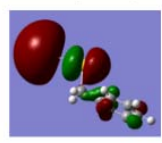

$\mathrm{Zn}^{2+}$ (HOMO)
Fig. 5 The stable configuration of sulfhydryl with heavy metal ions, and LUMO, HOMO

According to the Fig.5, it can be seen that the distribution of electron cloud between LUMO and HOMO of TPM and $\mathrm{Tl}^{+}$is more symmetric, indicating that the coordination ability is better. In the LUMO and HOMO diagrams, the electron cloud is mainly distributed on the $6 \mathrm{p}$ orbit of $\mathrm{Tl}^{+}$, and the bonding mode is $\pi$ bond. In addition, the frontier orbital energy of TPM and each heavy metal ion was calculated. The results are shown in the Table 2. The frontier orbital energy of TPM and $\mathrm{Tl}^{+}$is 0.1043 , and the frontier orbital energy of $\mathrm{Pb}^{2+}$ and $\mathrm{Zn}^{2+}$ is 0.07945 and 0.06425 , respectively. The energy is related to the strength of the chemical activity of the complex. The chemical activity increased as the energy fell, and the stability of the structure decreased, and vice versa. In this way, the binding ability of TPM and $\mathrm{Tl}^{+}$is the strongest, followed by $\mathrm{Pb}^{2+}$ and $\mathrm{Zn}^{2+}$.

Table 2 Sulfhydryl is associated with heavy metal ions in the front-line orbital energy

\begin{tabular}{|c|c|c|c|}
\hline Metal ions & E $_{\text {LUMO }}$ & Еномо $_{\text {Hо }}$ & $\Delta \mathrm{E}$ \\
\hline $\mathrm{Tl}^{+}$ & -0.0719 & -0.1962 & 0.1043 \\
\hline $\mathrm{Pb}^{2+}$ & -0.06487 & -0.14432 & 0.07945 \\
\hline $\mathrm{Zn}^{2+}$ & -0.09286 & -0.15711 & 0.06425 \\
\hline
\end{tabular}

In order to verify the calculation results, an adsorption competition experiment was carried out. As shown in Fig.6, the adsorption rate of TPM to $\mathrm{Tl}^{+}, \mathrm{Pb}^{2+}$, $\mathrm{Zn}^{2+}$ heavy metal ions are faster. Within 5 min of the test, the concentration of these heavy metal ions decreased by $85.84 \%, 53.17 \%$ and $65.75 \%$, respectively, and then gradually became stable, and the final concentration of $\mathrm{Tl}^{+}$was $3 \mu \mathrm{g} / \mathrm{L}$. The experimental results demonstrate that the metal ions bind to the active sites on the surface very quickly when they are in contact with the TPM. After the surface active sites are combined with the heavy metal ions, the ions adsorbed on the surface diffuse into the deep layers of the TPM and enter the slow phase. Thus, the adsorption rate of metal ions in the solution gradually stabilizes, and finally reaches the adsorption equilibrium. Therefore, the presence of other heavy metal ions will compete with $\mathrm{Tl}^{+}$for the adsorption site of TPM, which will have a certain influence on the adsorption performance of TPM to $\mathrm{Tl}^{+}$.

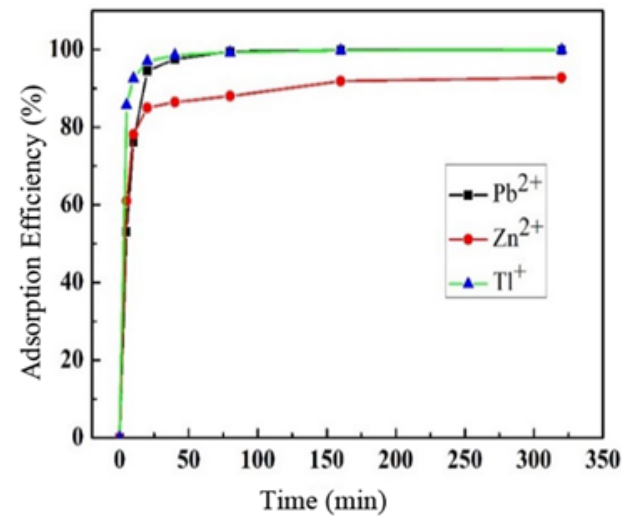

Fig.6 Effect of time on absorption capacity of $\mathrm{Pb}^{2+} 、 \mathrm{Zn}^{2+} 、 \mathrm{Tl}^{+}$by TPM

\subsection{Effect of adsorption conditions}

The effects of different dosage, treatment time, environmental $\mathrm{pH}$ and ambient temperature on the adsorption of by TPM were investigated. The variations in the removal efficiency of $\mathrm{Tl}^{+}$at different dosage are shown in Fig.7. The liquid-solid ratios are 0.2, 0.4, 0.6, 0.8 , and $1 \mathrm{~L} / \mathrm{g}$, respectively. It can be seen from the figure that when the concentration of $\mathrm{Tl}^{+}$is $5 \mathrm{mg} / \mathrm{L}$ and the liquid-solid ratio is $0.6 \sim 1.0 \mathrm{~L} / \mathrm{g}$, the concentration of $\mathrm{Tl}^{+}$was higher than $180 \mu \mathrm{g} / \mathrm{L}$ in remaining solution, which was much higher than the national emission standard of $5 \mu \mathrm{g} / \mathrm{L}$. This means that the concentration of $\mathrm{Tl}^{+}$in the wastewater after the reaction is lower than the national standard of $5 \mu \mathrm{g} / \mathrm{L}$. Under these conditions, the adsorption capacity of TPM to $\mathrm{Tl}^{+}$was calculated to be about $2.73 \mathrm{mg} / \mathrm{g}$. Compared with other adsorbent materials, the TPM prepared in this study has a higher adsorption capacity ${ }^{35}$. 


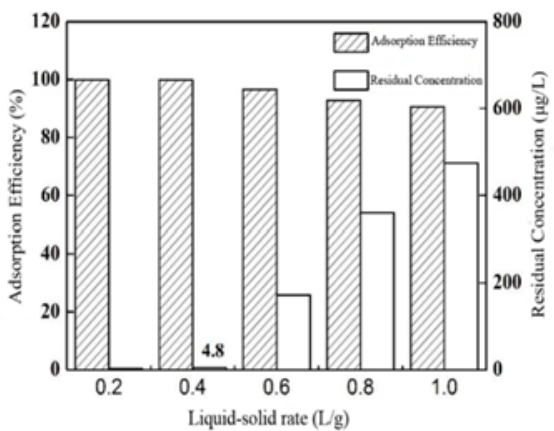

Fig.7 Effect of dosage on absorption capacity of Tl by TPM

Fig. 8 shows the effect of reaction time on $\mathrm{Tl}^{+}$ adsorption by TPM. The process of $\mathrm{Tl}^{+}$adsorption by TPM is segmental. In the initial 40min, the concentration of $\mathrm{Tl}^{+}$in the solution decreased rapidly, and the rate of adsorption reaction was fast. The rate of adsorption slowed down in the subsequent $120 \mathrm{~min}$, and then began to decrease rapidly until the adsorption equilibrium was reached at $640 \mathrm{~min}$, and the $\mathrm{Tl}^{+}$concentration was lowered to $3 \mu \mathrm{g} / \mathrm{L}$.

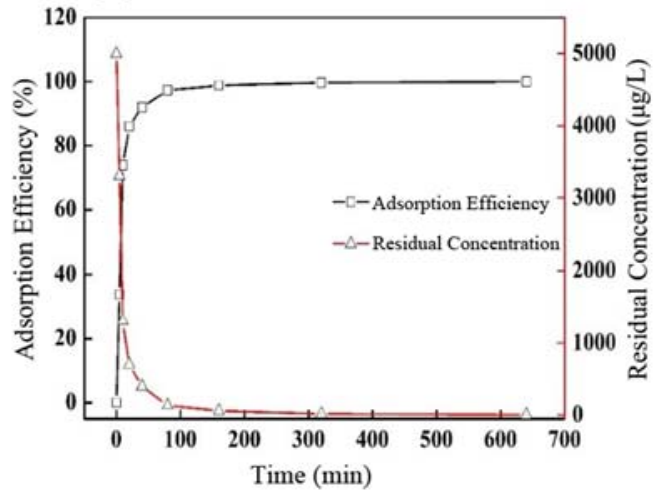

Fig. 8 Effect of time on absorption capacity of $\mathrm{Tl}^{+}$by TPM

The effect of different $\mathrm{pH}$ on the adsorption was also investigated (Fig.9). At the $\mathrm{Tl}^{+}$concentration of $5 \mathrm{mg} / \mathrm{L}$, the adsorption removal rate of $\mathrm{Tl}^{+}$by TPM is above $99.7 \%$

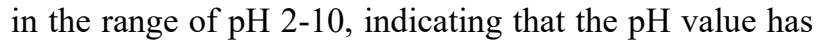
a weak influence on the adsorption process. After 640 min, the residual concentration of $\mathrm{Tl}^{+}$was $12.34 \mu \mathrm{g} / \mathrm{L}$ at $\mathrm{pH}=2$, which did not reach the national standard of $5 \mu \mathrm{g} / \mathrm{L}$. However, with the increase of $\mathrm{pH}$, the residual concentration of $\mathrm{Tl}^{+}$decreased continuously. When $\mathrm{pH}=6$, the remaining concentration is $4.41 \mu \mathrm{g} / \mathrm{L}$, which is lower than the national standard. At $\mathrm{pH}=10$, the residual concentration is $0.78 \mu \mathrm{g} / \mathrm{L}$, which is far lower than the national standard, indicating that the alkaline condition is beneficial to the adsorption of TPM to $\mathrm{Tl}^{+}$.

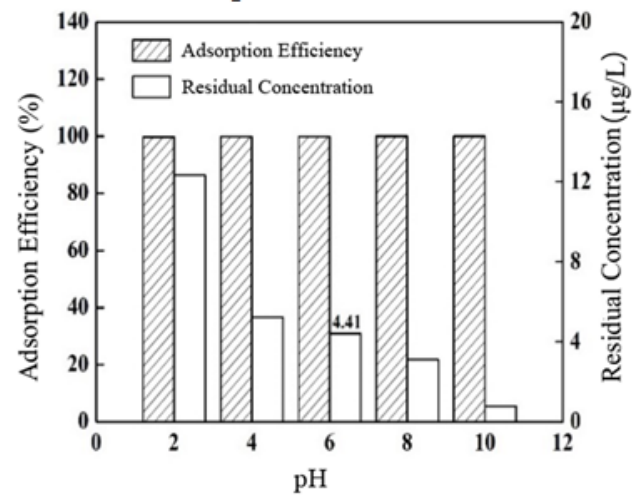

Fig.9 Effect of $\mathrm{pH}$ absorption capacity of $\mathrm{Tl}^{+}$by $\mathrm{TPM}$

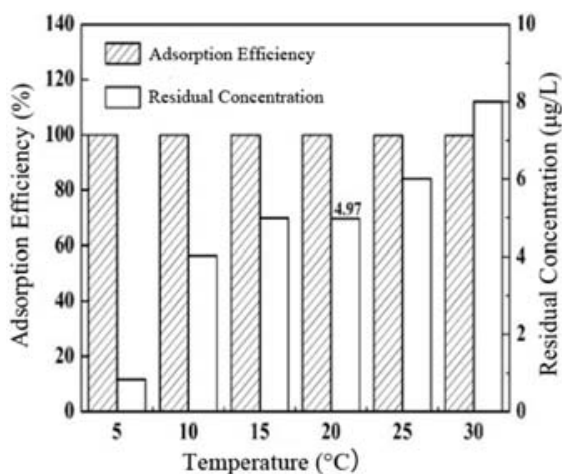

Fig.10 Different temperature on absorption capacity of $\mathrm{Tl}^{+}$by TPM

The adsorption performance of TPM on $\mathrm{Tl}^{+}$under different temperature conditions is shown in Fig.10. The removal rate of $\mathrm{Tl}^{+}$by TPM is above $99.7 \%$ when the temperature is in the range of $5-30{ }^{\circ} \mathrm{C}$, indicating that the temperature has little effects on the adsorption process in this study. When the reaction temperature is in the range of $5 \sim 20^{\circ} \mathrm{C}$, the residual concentration of $\mathrm{Tl}^{+}$is reduced from $4.97 \mu \mathrm{g} / \mathrm{L}$ to $0.83 \mu \mathrm{g} / \mathrm{L}$, which is lower than the national emission standard, suggesting that the lower temperature is beneficial to the adsorption of $\mathrm{Tl}^{+}$by TPM.

\subsection{Adsorption isotherm}

The adsorption isotherms were measured at 5, 15, and $25^{\circ} \mathrm{C}$ and were fitted by Langmuir, Freundlich and Dubinin-Radushkevich equations respectively. The fitting equation is as follows:

Langmuir $^{36,37}$ :

Freundlich ${ }^{38}$

$$
\frac{C_{e}}{q_{e}}=\frac{C_{e}}{q_{m}}+\frac{1}{b q_{m}}
$$

$$
\ln q_{e}=\frac{1}{n} \ln C_{e}+\ln K_{f}
$$

Dubinin-Radushkevich ${ }^{39-41}$ :

$$
\begin{gathered}
\ln q_{e}=\ln q_{m}+K_{D} \varepsilon^{2} \\
\varepsilon=\mathrm{RT} \ln \left(1+\frac{1}{C_{e}}\right) \\
\mathrm{E}=\frac{1}{\sqrt{-2 K_{D}}}
\end{gathered}
$$

Where $\mathrm{q}_{\mathrm{e}}$ is the theoretical adsorption amount, $\mathrm{mg} / \mathrm{g}$; $\mathrm{q}_{\mathrm{m}}$ is the empirically calculated unit mass adsorbent adsorption amount, $\mathrm{mg} / \mathrm{g} ; \mathrm{C}_{\mathrm{e}}$ is the concentration of the adsorbed substance in the solution, $\mathrm{mg} / \mathrm{L} ; \mathrm{K}_{\mathrm{f}}, \mathrm{n}$ is the Freundlich empirical constant; $\mathrm{K}_{\mathrm{D}}$ is related to the adsorption free energy, $\mathrm{mol}^{2} / \mathrm{kJ}^{2} ; \varepsilon$ is the Polanyi adsorption potential energy; $\mathrm{E}$ is the average adsorption energy, $\mathrm{kJ} \cdot \mathrm{mol}^{-1}$. As shown in Fig.11, the isothermal fitting curve of TPM adsorption T1+ has a good linear relationship, and the relevant fitting parameters are all above 0.95 , indicating that TPM adsorption of $\mathrm{Tl}^{+}$is monolayer adsorption, which is preferential adsorption, and the adsorption process is exothermic. 

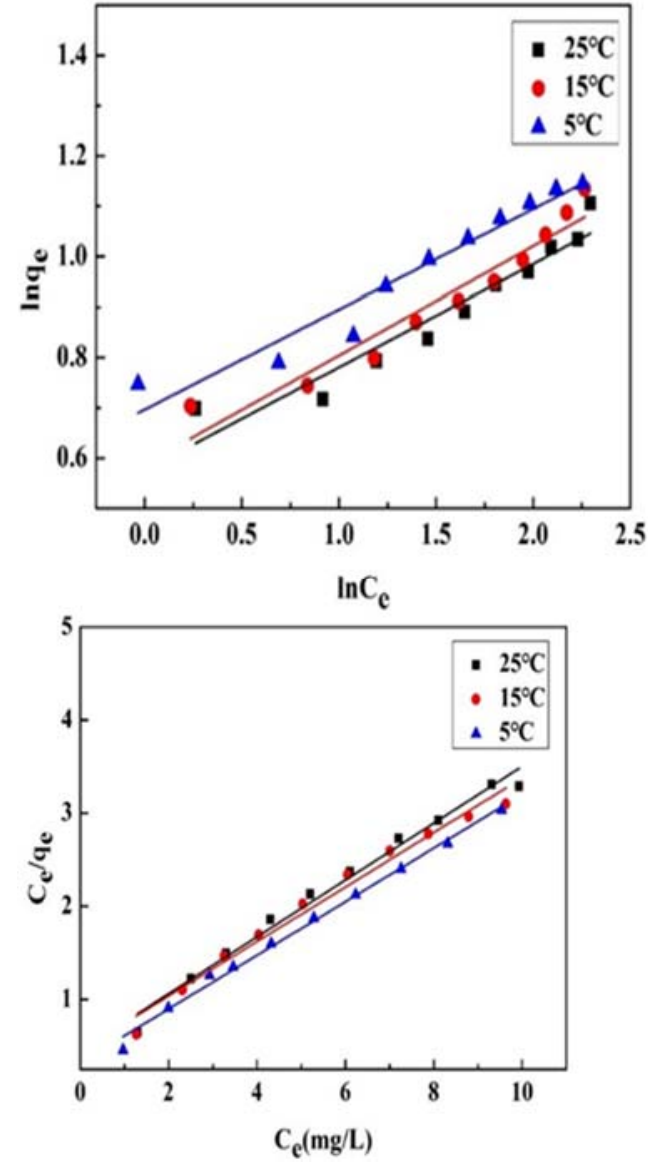

Fig.11 Langmuir isotherems for adsorption of $\mathrm{Tl}^{+}$on TPM

In addition, the free energy of adsorption can be calculated by fitting the results of DR isotherm. The values are shown in Table 3. The average adsorption energy obtained is between $15.63-18.14 \mathrm{~kJ} \cdot \mathrm{mol}-1$. According to the literature, the average adsorption energy is physical adsorption between 1.0-8.0, ion exchange adsorption between 9.0-16.0, and chemical adsorption above $16.0^{42,43}$. Therefore, the process of TPM adsorption by TPM is dominated by chemical reactions, supplemented by ion exchange.

Table $3 \mathrm{D}-\mathrm{R}$ isotherems parameters for adsorption of $\mathrm{Tl}^{+}$on

\begin{tabular}{cccc}
\multicolumn{4}{c}{ TPM } \\
\hline Temperature $\left({ }^{\circ} \mathrm{C}\right)$ & 25 & 15 & 5 \\
\hline $\mathrm{E}(\mathrm{kJ} / \mathrm{mol})$ & 18.14 & 17.08 & 15.63 \\
\hline
\end{tabular}

\subsection{Adsorption kinetics}

Fig.12 shows the kinetic curves of the adsorption process under different concentrations of $\mathrm{Tl}^{+}$and different $\mathrm{pH}$ conditions. The kinetics curves at different $\mathrm{pH}$ conditions can be divided into three stages. The first stage is $0-10$ min, which is the surface mass transfer stage and the adsorption rate is the fastest. The second stage occurs at 10-80 min, followed by the third stage, which reflects the diffusion of the adsorbate in the pore structure of the material during the adsorption process. Under different concentration conditions, it can also be divided into three stages, but the membrane diffusion stage time at a lower concentration is longer than that at a high concentration.
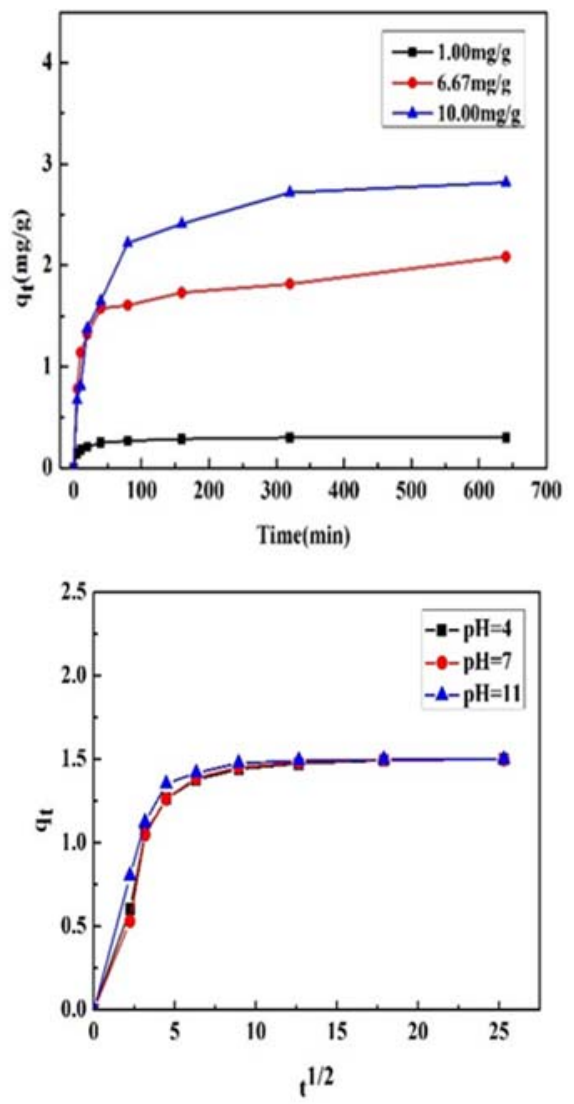

Fig.12 Particle diffusion model plots for the adsorption of $\mathrm{Tl}^{+}$ on TPM, $\mathrm{pH}=4,7,11 ; 1,6.67$ and $10 \mathrm{mg} / \mathrm{L}$

The results were fitted by quasi-second-order kinetic equation $^{44-46}$, and the fitting results are shown in Fig.13. The correlation coefficients are all above 0.999, which indicates that the adsorption process of $\mathrm{Tl}^{+}$by TPM can be used a good description of the stage dynamics under the experimental conditions.

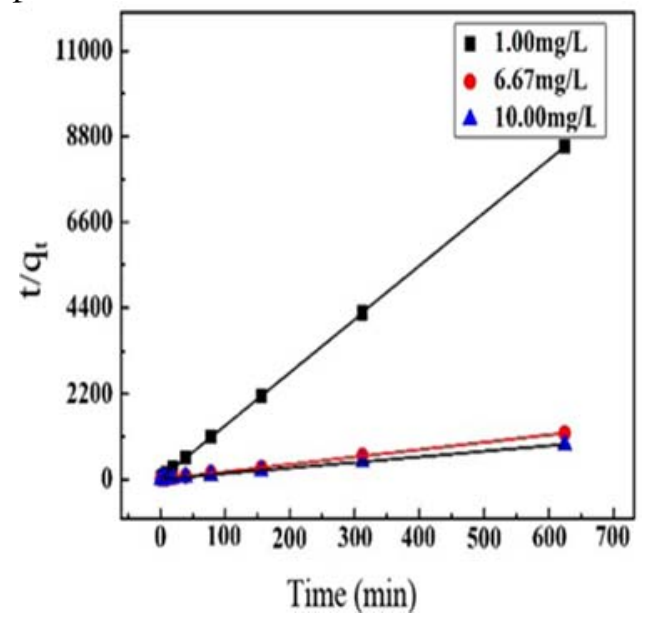




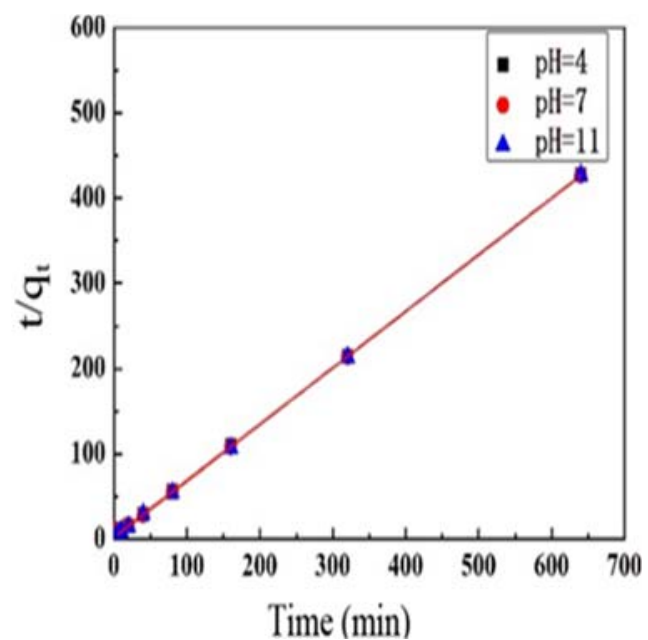

Fig.13 Pseudo-second-order kinetics plots for the adsorption of $\mathrm{Tl}^{+}$on TPM, $\mathrm{pH}=4,7,11 ; 1,6.67$ and $10 \mathrm{mg} / \mathrm{L}$

\subsection{Desorption and regeneration of TPM}

Desorption experiment was carried out in the presence of $0.1,0.2,0.3,0.4$ and $0.5 \mathrm{~mol} / \mathrm{L}$ of dilute sulfuric acid to investigate the desorption effect of different concentrations of reaction solution. As shown in Fig.14, the desorption rate of TPM increased gradually as the increase of sulfuric acid concentration, and the desorption efficiency increased from $89.38 \%$ to $99.96 \%$. When the sulfuric acid concentration is $0.5 \mathrm{~mol} / \mathrm{L}$, it is basically possible to desorb all $\mathrm{Tl}^{+}$on the TPM. The TPM was recycled in a $0.5 \mathrm{~mol} / \mathrm{L}$ sulfuric acid solution to investigate the regeneration performance of $\mathrm{Tl}^{+}$ adsorption by TPM. As displayed in Fig.15, the results suggested that the adsorption rate of TPM to $\mathrm{Tl}^{+}$ decreased from $99.93 \%$ to $99.83 \%$ after four cycles. This means that TPM has good cycle regeneration performance. Therefore, it can be proved that TPM is a highly efficient material for adsorbing $\mathrm{Tl}^{+}$and the regeneration performance is better.

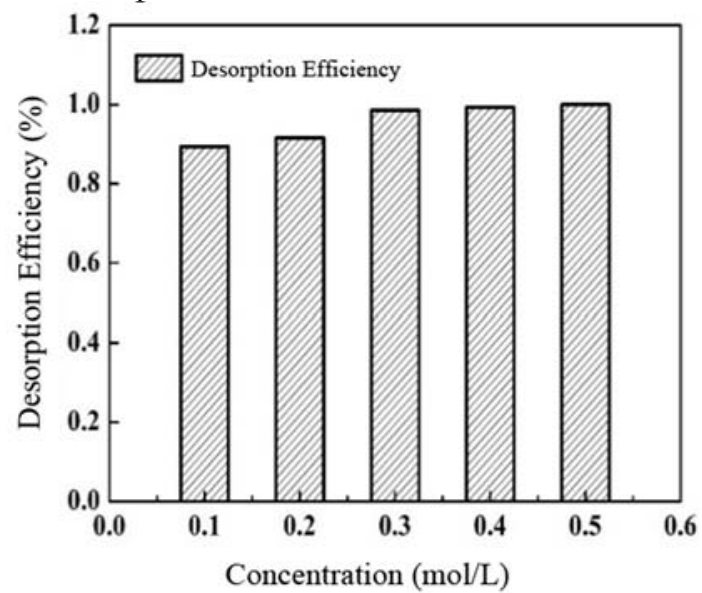

Fig.14 The efficiency of desorption with different concentration of desorption

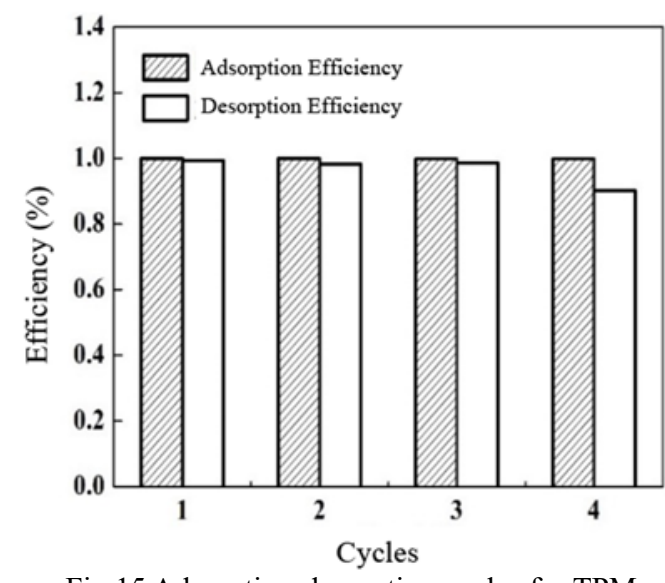

Fig.15 Adsorption-desorption cycles for TPM

\section{Conclusion}

In this study, chloromethylated polystyrene microspheres were used as raw materials to prepare efficient $\mathrm{Tl}^{+}$ adsorbents through thiol modification. The adsorption characteristics and mechanism of $\mathrm{Tl}^{+}$in solution under different conditions were studied. The main conclusions of the research in this paper are summarized as follows: Elemental analysis, Fourier Transform Infrared Spectrometer, and thermogravimetric analysis proved that the thiol groups were successfully grafted on the polystyrene microspheres surface and the TPM had good thermal stability. When the dosage of TPM is $0.4 \mathrm{~L} / \mathrm{g}, \mathrm{pH}$ is 6-10, temperature is $5-20{ }^{\circ} \mathrm{C}$, and adsorption time reaches $640 \mathrm{~min}$, thallium-containing water with $\mathrm{Tl}^{+}$ concentration of $5 \mathrm{mg} / \mathrm{L}$ can be treated to within the national discharge standard $(5 \mu \mathrm{g} / \mathrm{L})$. The analytical effect of $0.5 \mathrm{~mol} / \mathrm{L}$ dilute sulfuric acid on TPM can reach $99.96 \%$, and the adsorption capacity of $\mathrm{TPM}$ on $\mathrm{Tl}^{+}$is reduced by only $0.1 \%$ after repeated use 4 times. Raman analysis showed that the thiol peak disappeared after $\mathrm{Tl}^{+}$ was adsorbed by TPM, indicating that the functionality of the thiol group disappeared after the thiol group was successfully coordinated with $\mathrm{Tl}^{+}$. Langmuir fitting results showed that the maximum saturated adsorption capacity of the TPM was $3.47 \mathrm{mg} / \mathrm{g}$, and the adsorption process was exothermic. According to the results of kinetics studies, the adsorption experiment is dominated by chemical adsorption and supplemented by ion exchange. In addition, the intra-particle diffusion model show that the average value of the membrane diffusion coefficient and the pore diffusion coefficient is $1.68 \times 10^{-7}$ and $5.71 \times 10^{-7}$, indicating that the adsorption process is mainly controlled by membrane diffusion.

\section{Acknowledgements}

Thanks Feng Cong for completing part of the experimental operation and preliminary data collection.

\section{Funding}

The study was financially supported by Research and Development plan of key areas in Hunan Province: Key 
Technologies for Controlling Heavy Metal Pollution of Inlet River Water and Deep Purification of Antimony Micro-pollution (2019SK2281).

\section{References}

1. R. Tyagi, P. Rana, A. R. Khan, D. Bhatnagar, M. M. Devi, S. Chaturvedi, R. P. Tripathi and S. Khushu, Journal of Applied Toxicology, 2011, 31, 663-670.

2. A. R. Despić, D. M. Dražić, M. M. Purenović and N. Ciković, Journal of Applied Electrochemistry, 1976, 6, 527-542.

3. C. J. Rickwood, M. King and P. Huntsman-Mapila, Ecotoxicology and Environmental Safety, 2015, 115, 300-308.

4. A. K. Das, R. Chakraborty, M. L. Cervera and M. d. 1. Guardia, Analytical \& Bioanalytical Chemistry, 2006, 385, 665-670.

5. C. Easton, A. Turner and G. Sewell, Environmental Pollution, 2011, 159, 3504-3508.

6. A. L. J. Peter and T. Viraraghavan, Environment International, 2005, 31, 493-501.

7. M. J P, Veterinary and human toxicology, 1993, 35, 445-453.

8. T. Xiao, J. Guha, D. Boyle, C.-Q. Liu, B. Zheng, G. C. Wilson, A. Rouleau and J. Chen, Environment International, 2004, 30, 501-507.

9. R. Riyaz, S. L. Pandalai, M. Schwartz and Z. N. Kazzi, Journal of Medical Toxicology, 2013, 9, 75-78.

10. Xiong and Yongliang, Environmental Chemistry, 2009, 6, 441.

11. C. Casiot, M. Egal, O. Bruneel, N. Verma and F. Elbaz-Poulichet, Environmental Science \& Technology, 2011, 45, 2056-2064.

12. J. E. Dutrizac, T. T. Chen and S. Beauchemin, Hydrometallurgy, 2005, 79, 138-153.

13. T. Sato, Hydrometallurgy, 1992, 30, 367-383.

14. S. Shirazian, F. Fadaei and S. N. Ashrafizadeh, Solvent Extraction \& Ion Exchange, 2012, 30, 490-506.

15. T. Vincent, J.-M. Taulemesse, A. Dauvergne, T. Chanut, F. Testa and E. Guibal, Carbohydrate Polymers, 2014, 99, 517-526.

16. P. J. Faustino, Y. Yang, J. J. Progar, C. R. Brownell, N. Sadrieh, J. C. May, E. Leutzinger, D. A. Place, E. P. Duffy, F. Houn, S. A. Loewke, V. J. Mecozzi, C. D. Ellison, M. A. Khan, A. S. Hussain and R. C. Lyon, Journal of Pharmaceutical and Biomedical Analysis, 2008, 47, 114-125.

17. L. Zhang, T. Huang, M. Zhang, X. Guo and Z. Yuan, Journal of Hazardous Materials, 2008, 157, 352-357.

18. S. G. Nielsen, L. E. Wasylenki, M. Rehkämper, C. L. Peacock, Z. Xue and E. M. Moon, Geochimica et Cosmochimica Acta, 2013, 117, 252-265.

19. J. Zolgharnein, N. Asanjarani and T. Shariatmanesh, Toxicological \& Environmental
Chemistry Reviews, 2011, 93, 207-214.

20. H. Dashti and H. Aghaie, CLEAN - Soil, 2013, 41, 673-679.

21. J. Tang, W. Wu, L. Yu, X. Fan, G. Liu and Y. Yu, Science of The Total Environment, 2019, 694, 133625 .

22. R. F. Mueller, Mine Water and the Environment, 20, 17-29.

23. B. R. Reddy, S. V. Rao and K. H. Park, 22, 500-505.

24. Q. P. Y, D. G. L, D. S. S. Maris and E. L. B, Environmental science and pollution research international, 2019, 26, 32285-32297.

25. A. S. Amin, A.-A. M. El-Sharjawy and M. A. Kassem, Spectrochimica Acta Part A: Molecular and Biomolecular Spectroscopy, 2013, 110, 262-268.

26. D. Pelclova, P. Urban, P. Ridzon, Z. Senholdova, E. Lukas, P. Diblik and L. Lacina, Human \& Experimental Toxicology, 2009, 28, 263-272.

27. G. A. Kilic and M. Kutlu, Food \& Chemical Toxicology, 2010, 48, 980-987.

28. Y. Jin-hui, W. Jin-song, Z. Shu-kui, R. Lin and D. Qin-wen, Bioinformatics and Biomedical Engineering, 2010, DOI: 10.1109/ICBBE.2010.5517179, 1-4.

29. B. A. Utkelov, E. E. Ergozhin and R. K. Ashkeeva, Reactive Polymers, 1991, 14, 187-191.

30. M. Node, K. Kumar, K. Nishide, S.-i. Ohsugi and T. Miyamoto, Tetrahedron Letters, 2001, 42, 9207-9210.

31. D. Chen, L. Wang, Y. Ma and W. Yang, NPG Asia Materials, 2016, 8, 301.

32. G. S. Mandair, Z. Yu, N. Galaffu, M. Bradley and A. E. Russell, Applied Spectroscopy, 2004, 58, $1282-1287$.

33. R. Sanghi and P. Verma, Bioresource Technology, 2009, 100, 501-504.

34. T. Saegusa, S. Kobayashi, K. Hayashi and A. Yamada, Polymer Journal, 1978, 10, 403-408.

35. L. Zhang, T. Huang, N. Liu, X. Liu and H. Li, Microchimica Acta, 2009, 165, 73-78.

36. T. Powell, G. M. Brion, M. Jagtoyen and F. Derbyshire, Environmental Science \& Technology, 2000, 34, 2779-2783.

37. S. Luo, X. Xu, G. Zhou, C. Liu, Y. Tang and Y. Liu, Journal of Hazardous Materials, 2014, 274, 145-155.

38. B. K. Nandi, A. Goswami and M. K. Purkait, Journal of Hazardous Materials, 2009, 161, 387-395.

39. M. M. Dubinin, E. D. Zaverina and L. V. Radushkevich, Zhurnal Fizicheskoi Khimii, 1947, 21, 1351-1362.

40. G. Thirupathi, C. P. Krishnamoorthy and S. Pushpavanam, Chemical Engineering Journal, 2007, 125, 177-186.

41. Y. Seki, S. Seyhan and M. Yurdakoc, Journal of Hazardous Materials, 2006, 138, 60-66.

42. M. S. Onyango, Y. Kojima, O. Aoyi, E. C. 
Bernardo and H. Matsuda, Journal of Colloid and Interface Science, 2004, 279, 341-350.

43. I. Kiran, T. Akar, A. S. Ozcan, A. Ozcan and S. Tunali, Biochemical Engineering Journal, 2006, 31, 197-203.

44. D. Duranoğlu, A. W. Trochimczuk and U. Beker, Chemical Engineering Journal, 2012, 187,
193-202.

45. A. R. Tehrani-Bagha, H. Nikkar, N. M. Mahmoodi, M. Markazi and F. M. Menger, Desalination, 2011, 266, 274-280.

46. Z. Yin, Y. Liu, S. Liu, L. Jiang, X. Tan, G. Zeng, M. Li, S. Liu, S. Tian and Y. Fang, Science of The Total Environment, 2018, 639, 1530-1542. 